\title{
Immobilized Catalyst for Detecting Chemiluminescence in Lipid Hydroperoxide
}

\author{
Akira Wadano, Teturo Ikeda, Motonobu Matumoto \\ and Michio Himeno \\ Department of Agricultural Chemistry, College of Agriculture, \\ University of Osaka Prefecture, Sakai, \\ Osaka 591, Japan
}

Received July 9, 1990

\begin{abstract}
Both microperoxidase and cytochrome $c$ could be immobilized on a gel for HPLC without losing their activity, the specificity of each immobilized catalyst being similar to that of the free catalyst. With up to $40 \%$ of methanol, the chemiluminescence increased as the alcohol concentration increased, while the count decreased with more than $10 \%$ methanol for the free cytochrome $c$. When used as the reactant for flow injection analysis, they do not need to occupy the cell for the emission of chemiluminescence. The immobilized reactant can measure from $400 \mathrm{pmol}$ to $10 \mathrm{nmol}$ of tertbutylhydroperoxide $(t-\mathrm{BuOOH})$ without staining the emission cell.
\end{abstract}

Kaschnitz and Hatefi ${ }^{11}$ have reported that electron transfer proteins work as initiators of lipid autoxidation. In their paper, they also mentioned that the oxidized hemes were much more active than their ferrous counterparts, and that smaller compounds were more effective than the larger hemoproteins. The smaller heme compounds also achieved high sensitivity in the oxidation systems for chemiluminescent compounds. ${ }^{2)}$ An oxidation system with microperoxidase as the catalyst was used as a chemiluminescence detector for lipid hydroperoxides, which were identified by high-performance liquid chromatography (HPLC) ${ }^{3)}$ On the other hand, Miyazawa et al. found that cytochrome $c$ was a good catalyst for chemiluminescence reactions of long fatty acid chain hydroperoxide at $\mathrm{pH} 9.3$. $^{4}$ They also applied the system as a chemiluminescence detector for HPLC of lipid hydroperoxide. ${ }^{5)}$ However, microperoxidase is expensive as a post-label chemiluminescence reagent for HPLC, while cytochrome $c$ is not very soluble in the mobile phase of HPLC for separating the hydroperoxides. After a hydrophilic soIution of cytochrome $c$ has been mixed with the hydrophobic mobile phase, cytochrome $c$ may attach to the spiral chemiluminescence cell. Thus, immobilization of the catalysts may save the quantity of microperoxidase or prevent staining of the cell by cytochrome $c$.

Catalysts and reagents for chemiluminescence have been immobilized on transparent materials such as glass ${ }^{6,7)}$ or polyacrylamide gel. ${ }^{8)}$ Chemiluminescence analysis in flowing streams, however, does not necessarily need the catalyst in the cell to detect light. If it is possible to position the immobilized catalyst before the light-detecting cell in flowing streams, it would make easiest to select the materials for immobilizing the catalyst and to construct the cell.

The primary aim of this study is to discover whether catalysts can be immobilized while retaining their activity and to check their characteristics. It will also checked whether the immobilized catalyst works in a hydrophobic medium and whether it must occupy the cell.

Abbreviations: DMAB, dimethylaminoborane; HPLC, high-performance liquid chromatography; LOOH, 13-hydroperoxylinoleic acid; MOPS, 3-( $N$-morpholino)propanesulfonic acid; SCBH, sodium cyano borohydride; $t$-BuOOH, tert-butylhydroperoxide; TLC, thin-layer chromatography. 


\section{Materials and Methods}

Reagents. Microperoxidase and cytochrome $c$ (type IV) were obtained from Sigma Chemical Company, and Affi-prep 10 from Bio-Rad Laboratories Co., Ltd. Epoxy-Toyopearl 650M, AF Formyl-Toyopearl 650M, and AF Tresyl-Toyopearl $650 \mathrm{M}$ were purchased from Tosoh Corp. Sodium cyanoborohydride $\left(\mathrm{NaCNBH}_{3}\right.$; $\mathrm{SCBH}$ ) was obtained from Aldrich Chemical Co., Ltd., and dimethylaminoborane $\left(\left(\mathrm{CH}_{3}\right)_{2} \mathrm{HNBH}_{3} ; \mathrm{DMAB}\right)$ from Tokyo Kasei Co., Ltd. All other chemicals were purchased from Wako Pure Chemical Industries Ltd.

Preparation of reagents. For HPLC, the stock solutions of luminol and isoluminol contained $100 \mu \mathrm{g}$ of the compounds in $1 \mathrm{ml}$ of $0.1 \mathrm{M}$ Tris- $\mathrm{HCl}$ buffer, $\mathrm{pH} 9.0$. The stock solutions were kept in the dark at $4^{\circ} \mathrm{C}$, and used within one month. The solution was diluted to $1 \mu \mathrm{g} / \mathrm{ml}$ with $50 \mathrm{~mm}$ borate buffer, $\mathrm{pH} 9.3$ for luminol and $\mathrm{pH} 10.0$ for isoluminol, to use in the post column. This solution was freshly made up each time.

Immobilization of microperoxidase and cytochrome c. One $\mathrm{ml}$ of Affi-prep 10 slurry was suction-washed with $10 \mathrm{ml}$ each of 2-propanol, $10 \mathrm{~mm} \mathrm{Na-acetate} \mathrm{buffer,} \mathrm{pH} \mathrm{4.5}$, and $0.1 \mathrm{M}$ 3-( $N$-morpholino)propanesulfonic acid (MOPS) buffer, $\mathrm{pH} 7.5$. The filtrated gel was then suspended in $2 \mathrm{ml}$ of $0.1 \mathrm{~m}$ MOPS buffer, $\mathrm{pH} 7.5$, containing $5 \mathrm{mg}$ of microperoxidase. After incubating at $4^{\circ} \mathrm{C}$ overnight, $0.1 \mathrm{ml}$ of $1 \mathrm{M}$ ethanolamine was added to the suspension to block the remaining $N$-hydroxysuccinide esters of the gel. The completed absorbent was successively and fully washed with distilled water, $0.1 \mathrm{M} \mathrm{NaCl}$, and $0.1 \mathrm{M}$ MOPS buffer, $\mathrm{pH} 7.5$, and then stored at $4^{\circ} \mathrm{C}$ in $0.1 \mathrm{M}$ MOPS buffer, $\mathrm{pH}$ 7.5 .

AF Epoxy-Toyopearl $(0.5 \mathrm{~g})$ was swollen in distilled water, suction-washed with $0.2 \mathrm{M} \mathrm{NaHCO}_{3}, \mathrm{pH} 11.0$. The filtered gel was then suspended in $2 \mathrm{ml}$ of $0.2 \mathrm{M} \mathrm{NaHCO}_{3}$, pH 11.0, containing $5 \mathrm{mg}$ of microperoxidase. After incubating at $37^{\circ} \mathrm{C}$ for $14 \mathrm{hr}$ with shaking, the gel was extensively washed with distilled water and $1 \mathrm{M} \mathrm{NaCl}$. The gel was finally resuspended in $2 \mathrm{ml}$ of $0.1 \mathrm{M}$ phosphate buffer, $\mathrm{pH} 7.0$, containing $1 \mathrm{M}$ ethanolamine and incubated overnight to block any remaining epoxy groups.

AF Tresyl-Toyopearl $650 \mathrm{M}, 0.4 \mathrm{~g}$ of dry gel, was swollen and washed with distilled water and $0.1 \mathrm{M} \mathrm{NaHCO}, \mathrm{pH}$ 8.0 , containing $5 \mathrm{mg}$ microperoxidase or $40 \mathrm{mg}$ cytochrome c. After incubation overnight at room temperature with shaking, the gel was dried under suction. Then the gel was resuspended in $2 \mathrm{ml}$ of $0.2 \mathrm{M}$ phosphate buffer, $\mathrm{pH} 7.0$ containing $1 \mathrm{M}$ ethanolamine and incubated at room temperature for $2 \mathrm{hr}$ with shaking to block remaining any tresyl groups.

Measurement of the amount of immobilized reactant. The amount of immobilized microperoxidase was determined by the absorbance at $406 \mathrm{~nm}$ of the microperoxidase-gel suspension. ${ }^{9)}$ The amount of immobilized cytochrome $c$ was estimated from the amount of the free and total cytochrome $c$ used. The free cytochrome $c$ was measured by its absorbance at $410 \mathrm{~nm}$. ${ }^{10}$

Preparation of 13-hydroperoxylinoleic acid ( $\mathrm{LOOH})$. LOOH was obtained by the method of Rosa and Franke, ${ }^{11}$ with some modification. Forty $\mathrm{mg}$ of linoleic acid in $0.1 \mathrm{M} \mathrm{NH}_{4} \mathrm{OH}$ was mixed with $25 \mathrm{ml}$ of $0.1 \mathrm{M}$ sodium borate buffer, $\mathrm{pH} 9.0$, containing 20,000 units $/ \mathrm{ml}$ of lipoxygenase (lipoxygenase solution), and $\mathrm{O}_{2}$ was bubbled through at $0^{\circ} \mathrm{C}$ for $15 \mathrm{~min}$. Then, $5 \mathrm{ml}$ of the lipoxygenase solution was added to the mixture and $\mathrm{O}_{2}$ was bubbled at $0^{\circ} \mathrm{C}$ for $15 \mathrm{~min}$ more while stirring. The progress of the reaction was followed by the absorbance at $234 \mathrm{~nm}$ of the conjugated double bond of $\mathrm{LOOH}$ (molar coefficient $=26,000 \mathrm{~mol}^{-1} \cdot 1 \cdot \mathrm{cm}^{-1}$ ). After adding $150 \mathrm{ml}$ of cool ethanol, the mixture was immediately diluted with the same volume of water and acidified to $\mathrm{pH}$ 3.0 by $1 \mathrm{~N} \mathrm{HCl}$. Then, after extracting with $100 \mathrm{ml}$ of ethylether three times, the ether fraction was washed with water until the washings became neutral. The ether fraction was evaporated under vacuum and then desiccated by anhydrous $\mathrm{Na}_{2} \mathrm{SO}_{4}$. The residue was dissolved in $50 \mathrm{ml}$ of ethanol and kept at $-25^{\circ} \mathrm{C}$ under $\mathrm{N}_{2}$ gas. The purity of $\mathrm{LOOH}$ was measured by $\mathrm{TLC}^{12)}$ using a silica gel 60 F254 TLC plate (Merck Co., Ltd., $0.25 \mathrm{~mm}$ ) and developing with $n$-hexane-ethylether-acetate $=8$ : $7: 0.1$. The concentration of $\mathrm{LOOH}$ was determined by the iodometric method. ${ }^{13)}$ Under $\mathrm{N}_{2}$ gas, $35 \mathrm{ml}$ of a chloroform-acetate $(2: 3)$ mixture was added to $1 \mathrm{ml}$ of $\mathrm{LOOH}$, the resulting mixture being stirred vigorously for $1 \mathrm{~min}$ and then stood for $5 \mathrm{~min}$ at room temperature in the dark. Distilled water $(75 \mathrm{ml})$ was added, and the solution titrated with $0.01 \mathrm{~N}$ sodium thiosulfate, using $1 \%$ starch as the indicator. Standard $0.1 \mathrm{~N}$ sodium thiosulfate was diluted, with the distilled water replaced by $\mathrm{N}_{2}$, to prepare $0.01 \mathrm{~N}$ sodium thiosulfate for the titration. Titration was ended when the blue-green color of the starch had disappeared, the values obtained agreeing with the value obtained from the absorbance at $234 \mathrm{~nm}$.

Chemiluminescence detector. Chemiluminescence was detected with an instrument made by Wako Pure Chemical Industries, counting being done with an Iwatsu SC-7201 Universal Counter connected to an NEC PC-9801 personal computer by a GPIB interface. The detector has a magnetic stirrer under the cell holder when used to measure the chemiluminescence of a suspension like that of an immobilized catalyst. Reagents were prepared by the method of Schroeder et al. ${ }^{2)}$ To remove the chemiluminescence originating from the reaction mixture itself, a mixture containing $0.8 \mathrm{ml}$ of borate buffer, $\mathrm{pH} 9.0,0.1 \mathrm{ml}$ of luminol solution, and $0.1 \mathrm{ml}$ of the immobilized catalyst suspension was incubated for $5 \mathrm{~min}$ at room temperature. Adding a varying volume of $t$-BuOOH started the measurement of chemiluminescence, which was tested 


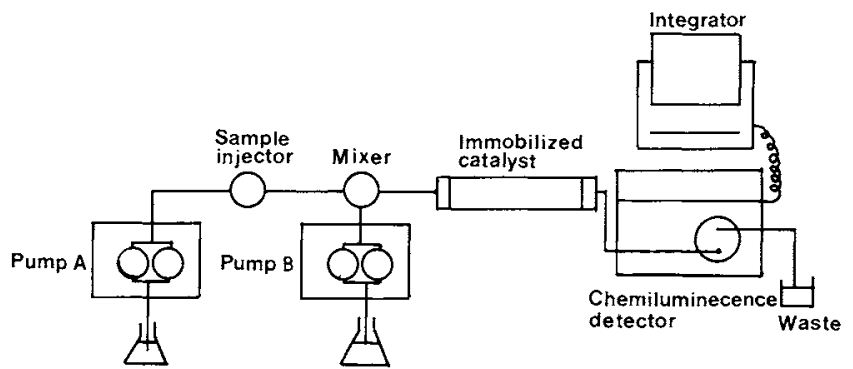

Fig. 1. Diagram of Flow the Injection Analysis System.

Pump A was used to pump the peroxide carrier liquid at a rate of $1.1 \mathrm{ml} / \mathrm{min}$, the liquid containing methanol-chloroform ( $9: 1$ by volume). Pump B was used to pump the chemiluminescent reagent, which contained $1 \mu \mathrm{g} / \mathrm{ml}$ of luminol in $50 \mathrm{~mm}$ borate buffer, $\mathrm{pH} 9.3$, at a flow rate of $1.0 \mathrm{ml} / \mathrm{min}$. The system includes a mixer, sample injector, immobilized catalyst, chemiluminescence detector, and integrator.

every $10 \mathrm{sec}$, the data being analyzed by a program prepared in our laboratory.

Flow injection analysis system. Flow injection analyses of the lipid peroxides were done by the method of Yamamoto et $a l .^{3)}$ and Miyazawa et al. ${ }^{5)}$ modified to suit the system, which included a DV-312 injector, JASCO 825-CL detector, HPLC pump model 576 \& APUS-8 (Gasukuro Co., Ltd.), and a KZU-1 mixer (Kyowaseimitsu Co., Ltd.) arranged as shown in Fig. 1. The immobilized microperoxidase or cytochrome $c$ was packed into a stainless column $(4 \times 100 \mathrm{~mm})$ under $10 \mathrm{~kg}$ of constant pressure and used as the chemiluminescence reaction reactor. The data were analyzed with a Shimadzu CR-6A Integrator Chromatopac (Shimadzu Co., Ltd.). A chloroform-methanol mixture $(1: 9, \mathrm{v} / \mathrm{v})$ was used as the carrier solution for flow injection analysis, the flow rate of the carrier and reaction solution being $1.1 \mathrm{ml} / \mathrm{min}$ and $1.0 \mathrm{ml} / \mathrm{min}$, respectively. The reaction solution contained $1 \mu \mathrm{g} / \mathrm{ml}$ of isoluminol or luminol in $50 \mathrm{~mm}$ of borate buffer, pH 10.0 or 9.3 .

Reduction and reoxidation of immobilized cytochrome $c$. Tresyl-Toyopearl ferricytochrome $c$ packed into the column was reduced with $1 \mathrm{~mm}$ ascorbic acid at $1.0 \mathrm{ml} / \mathrm{min}$ for $1 \mathrm{hr}$ and then washed with $0.1 \mathrm{M}$ phosphate buffer, $\mathrm{pH} 7.0$, at $1.0 \mathrm{ml} / \mathrm{min}$ for $1 \mathrm{hr}$. The Tresyl-Toyopearl ferricytochrome $c$ was re-oxidized with $1 \mathrm{~mm}$ potassium ferricyanate at a flow rate of $1 \mathrm{ml} / \mathrm{min}$ for $1 \mathrm{hr}$, and then washed with $0.1 \mathrm{M}$ phosphate buffer, $\mathrm{pH} 7.0$, at a flow rate of $1 \mathrm{ml} / \mathrm{min}$ for $1 \mathrm{hr}$.

\section{Results}

\section{Immobilization of the catalysts}

The amount of catalyst on each gel is shown in Table $\mathrm{I}$. The ratio of immobilized microperoxidase to total microperoxidase varied in
Table I. Amounts of Immobilized Catalyst on Each Gel

\begin{tabular}{ccc}
\hline & \multicolumn{2}{c}{ Ligand } \\
\cline { 2 - 3 } Carrier & Microperoxidase & Cytochrome $c$ \\
\hline Affi-prep 10 & $32 \%$ & \\
Epoxy-Toyopearl & $11 \%$ & \\
Formyl-Toyopearl & & $74 \%^{a}$ \\
with SCBH & $95 \%$ & $71 \%^{a}$ \\
with DMAB & $65 \%$ & $49 \%^{b}$ \\
Tresyl-Toyopearl & $83 \%$ & \\
\hline
\end{tabular}

a Estimated by the absorbance at $280 \mathrm{~nm}$.

$b$ Estimated as the mean of data measured for the absorbance at $280 \mathrm{~nm}$ and $407 \mathrm{~nm}$.

a wide range. While the ratio was $32 \%$ in the case of Affi-prep 10, the immobilized catalysts retained catalytic activity. Formyl-Toyopearl was a good gel for immobilizing the catalyst, but the immobilized catalyst was irreversibly reduced and lost its catalytic activity when using either SCBH or DMAB as the reductant. When cytochrome $c$ was used as the ligand, the immobilized cytochrome $c$ retained its activity with both reductants.

\section{Activity of the immobilized chemilumines- cence catalyst}

Figure 2 shows the time course of chemiluminescence for Affi-prep 10 microperoxidase, the chemiluminescence increasing depending on the amount of $t$-BuOOH from 10 to $50 \mathrm{nmol}$, and reaching a maximum $50 \mathrm{sec}$ after the 


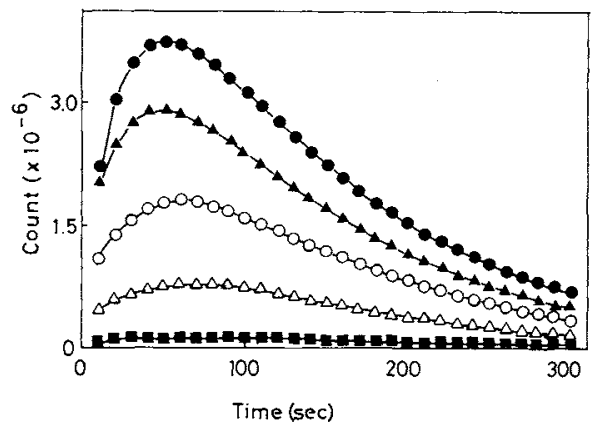

Fig. 2. Dependence of Chemiluminescence with Time for Affi-prep-microperoxidase on $t$ - $\mathrm{BuOOH}$.

The reaction mixture contained $0.4 \mathrm{~mm}$ luminol, $0.1 \mathrm{~m}$ borate buffer, $\mathrm{pH} 10.0$, and various amounts of $t-\mathrm{BuOOH}$ in a final volume of $1.0 \mathrm{ml}$. The amounts of $t-\mathrm{BuOOH}$ were $10 \mathrm{nmol}(\mathbf{C}), 20 \mathrm{nmol}(\triangle), 30 \mathrm{nmol}(\mathrm{O}), 40 \mathrm{nmol}$ $(\boldsymbol{A})$, and $50 \mathrm{nmol}(\boldsymbol{O})$.

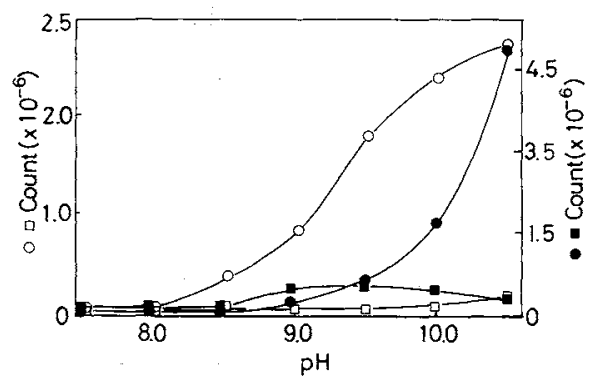

Fig. 3. $\mathrm{pH}$ Dependence of Chemiluminescence Intensity for $t$-BuOOH and $\mathrm{LOOH}$.

The reaction mixture contained $0.4 \mathrm{~mm}$ luminol, $10 \mathrm{nmol}$ $t$ - $\mathrm{BuOOH}$ (open symbols) or $1 \mathrm{nmol} \mathrm{LOOH}$ (closed symbols), and $0.1 \mathrm{M}$ buffer of various $\mathrm{pH}$ values in final volume of $1 \mathrm{ml}$. The buffers used were $0.1 \mathrm{M}$ Tris $-\mathrm{HCl}$ for $\mathrm{pH} 7.0-8.5,0.1 \mathrm{M}$ borate for $\mathrm{pH} 9.0-10.0$, and $0.1 \mathrm{M}$ carbonate for $\mathrm{pH}$ 10.5. Tresyl-Toyopearl microperoxidase (circle) and Tresyl-Toyopearl-cytochrome $c$ (square) were used as the immobilized catalysts.

reaction had started. The relative counts were estimated by a count for $10 \mathrm{sec}$ near the maximum chemiluminescence, or for $50 \mathrm{sec}$ from the beginning of the reaction, and these relative counts correlated well with the amount of $t-\mathrm{BuOOH}$. A quantitative comparison of the intensity of chemiluminescence catalyzed by the free and immobilized microperoxidase were not possible, because free catalyst showed its maximum chemiluminescence at $0 \mathrm{sec}$ in our system. However, the intensity of chemiluminescence catalyzed by the immobilized cyto-
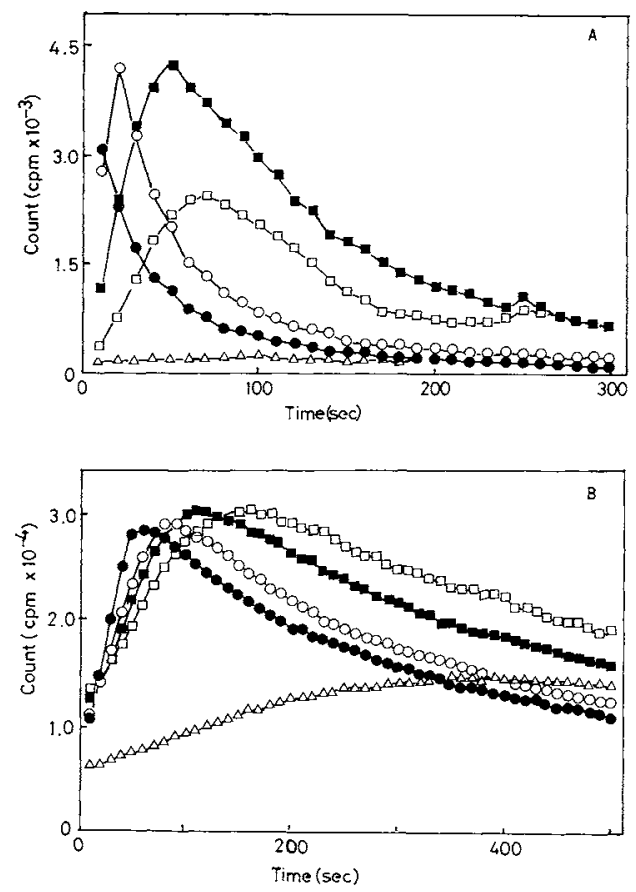

Fig. 4. Effect of Methanol on the Chemiluminescence with Free and Immobilized Cytochrome $c$.

(A) free cytochrome $c$; methanol concentrations were $0 \%$

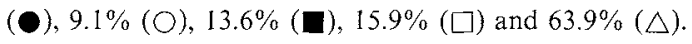
(B) Tresyl-Toyopearl cytochrome $c$; methanol concentrations were $0 \%(\boldsymbol{O}), 9.1 \%(\bigcirc), 18.2 \%(\square), 36.4 \%$ ( $\square)$ and $63.6 \%(\triangle)$.

chrome $c$ generally showed a higher steadystate level than that catalyzed by the free catalyst by about one order as shown in Fig. 3 .

\section{The effect of methanol on the chemiluminescence}

For the immobilized catalysts to be useful for analyzing $\mathrm{LOOH}$, the catalysts should retain their activity in the organic solvents that are usually used as the elution solvents for HPLC. As methanol is often used as a solvent, its effect (Fig. 3) on the chemiluminescence of $t$-BuOOH was checked by using free and Tresyl-Toyopearl cytochrome $c$. The immobilized cytochrome $c$ tolerated higher methanol concentrations. With up to $40 \%$ of methanol, the luminescence increased as the alcohol concentration increased with the immobilized catalyst, while the count decreased with more than $10 \%$ methanol with the free catalyst. 

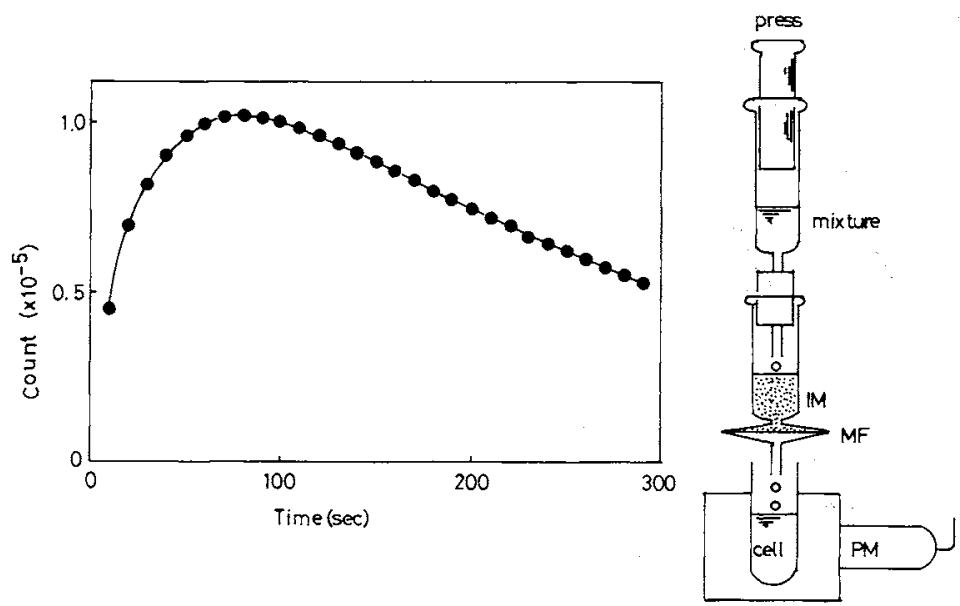

Fig. 5. Time Course of Luminol Chemiluminescence after the Reaction with $t$-BuOOH.

Also shown is the apparatus used for measuring the included immobilized microperoxidase (IM) via a millipore filter (MF) and photomultiplier (PM) in the chemiluminescence detector system. The mixture contained $0.1 \mathrm{ml}$ of $4 \mathrm{~mm}$ luminol, $0.9 \mathrm{ml}$ of $0.1 \mathrm{M}$ borate buffer, $\mathrm{pH} 10.0$, and $10 \mu \mathrm{l}$ of $1 \mathrm{~mm} t$-BuOOH.

\section{Optimum $\mathrm{pH}$ for the chemiluminescence}

To measure the $\mathrm{pH}$ optimum of the immobilized catalyst, we used $0.1 \mathrm{M}$ Tris- $\mathrm{HCl}$ buffer from $\mathrm{pH} 7.0$ to $8.5,0.1 \mathrm{M}$ borate buffer from $\mathrm{pH} 9.0$ to 10.0 , and $0.1 \mathrm{M}$ sodium bicarbonate buffer to $\mathrm{pH} 10.0$. Each count of chemiluminescence was measured for the first $50 \mathrm{sec}$, using $t$ - $\mathrm{BuOOH}$ as the peroxide (Fig. 4). At higher $\mathrm{pH}$ values, the chemiluminescence increased, especially for Tresyl-Toyopearl microperoxidase; at $\mathrm{pH} 10.0$, it was about 25-fold more than that for Tresyl-Toyopearl cytochrome $c$. Figure 4 shows the dependency of the chemiluminescence of $\mathrm{LOOH}$ on $\mathrm{pH}$ value. The activity of Tresyl-Toyopearl microperoxidase increased as the $\mathrm{pH}$ value increased up to 10.0, while that of Tresyl-Toyopearl cytochrome $c$ reached its maximum at $\mathrm{pH}$ 9.0. Thus the $\mathrm{pH}$ dependency of cytochrome $c$ was not changed by immobilization from that of free cytochrome $c .^{4 \text { ) }}$

Use of the immobilized catalysts for flow injection analysis

The chemiluminescence was detected batchwise by stirring a suspension of each immobilized catalyst and reagent in the same cell. If the emission of chemiluminescence is possible without the catalyst itself being at the site of emission, a flow injection cell can easily be constructed for the immobilized reactant. An assembly to study this is shown in the Fig. 5. The catalyst was packed in a $2 \mathrm{ml}$ luer-lock syringe with a membrane filter $(0.45 \mu \mathrm{m})$. A mixture of luminol and hydroperoxide was put onto the catalyst, the filtrate was collected in the counting cell, and the luminescence was then counted. The results for Affi-prepmicroperoxidase are shown in Fig. 5, the time profile of chemiluminescence resembling the result with a suspension of the immobilized catalyst. The maximum of chemiluminescence was about $80 \%$ of that with the suspension of the immobilized catalyst.

\section{Flow injection analysis of $t-B u O O H$ and lipid hydroperoxide}

While $400 \mathrm{pmol}$ to $10 \mathrm{nmol}$ of $t$-BuOOH was the linear range for measurement by flow injection with Tresyl-Toyopearl microperoxidase as the catalyst (Fig. 6A), the linear range was $5 \mathrm{nmol}$ to $90 \mathrm{nmol}$ with Tresyl-Toyopearlcytochrome $c$ (Fig. 6B). After Tresyl-Toyopearlcytochrome $c$ had been reduced with ascorbic acid, the chemiluminescence was decreased by up to $38 \%$. Reoxidizing the immobilized cytochrome $c$ with potassium ferricyanide restored the chemiluminescence to $77 \%$. Lipid peroxide 

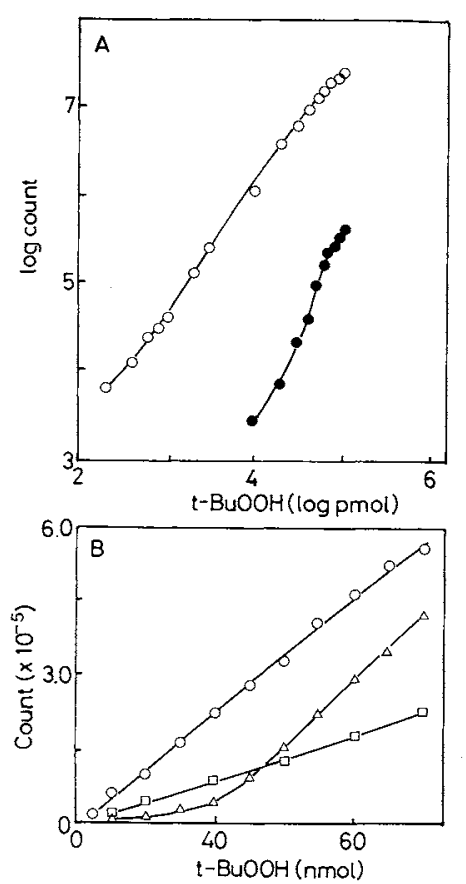

Fig. 6. Calibration Curves for $t$-BuOOH in the Flow Injection Analysis.

(A) Tresyl-Toyopearl-microperoxidase was used as the immobilized catalyst with buffers at $\mathrm{pH} 10.0(\mathrm{O})$ and $\mathrm{pH}$ 9.3

(B) Tresyl-Toyopearl-cytochrome $c$ was used as the immobilized catalyst. The data were obtained with untreated Tresyl-Toyopearl-cytochrome $c(O)$, after which the cytochrome $c$ was reduced with $1 \mathrm{~mm}$ ascorbate $(\square)$, and finally re-oxidized with $1 \mathrm{~mm}$ potassium ferricyanide $(\triangle)$.

was analyzed by using Tresyl-Toyopearlmicroperoxidase or Tresyl-Toyopearl-cytochrome $c$ as the catalyst. In contrast with the case for $t-\mathrm{BuOOH}$, there was not much difference in ability as a catalyst for chemiluminescence between the immobilized microperoxidase and cytochrome $c$ (Fig. 7). The operational stability of each immobilized catalyst in the column was studied with regular use. After 7 days, no activity change was detectable, although the resin at the top of the column had faded from its reddish brown color. On the other hand, immobilized cytochrome $c$ showed no change of color or activity after a month. However, a high concentration of peroxide passed through the column resulted in the

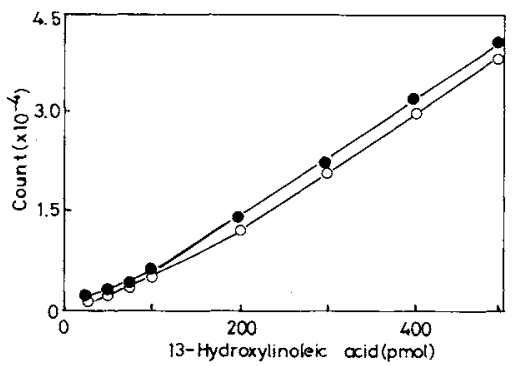

Fig. 7. Calibration Curves for LOOH by a Flow injection Analysis with Immobilized Catalysts.

The data were obtained with Tresyl-Toyopearl-microperoxidase (O) and Tresyl-Toyopearl-cytochrome $c(O)$ as the immobilized catalysts. All the other conditions are the same as those in Fig. 6.

immobilized catalysts losing their activity.

\section{Discussion}

Even if the catalyst was not in the chemiluminescence cell, the time dependency of chemiluminescence showed a peak at $50 \mathrm{sec}$ after the luminol and peroxide mixture had been passed through the immobilized catalyst. Singlet oxygen is generated rapidly by a Russel reaction between microperoxidase and $t$ $\mathrm{BuOOH},{ }^{9,14)}$ and this singlet oxygen has a life time of $2 \mu \mathrm{sec}{ }^{15)}$ This means that the limiting step of chemiluminescence may be the reaction in which the dioxsetan of luminol is oxidized to emit light. Figure 7 shows that immobilized microperoxidase worked more effectively as the catalyst for chemiluminescence with $t$ - $\mathrm{BuOOH}$ than did immobilized cytochrome $c$. However, there was no difference in the efficiency when lipid peroxide was used as the substrate (Fig. 7). The sensitivity for chemiluminescence with lipid peroxide was about 8 -fold that of $t$-BuOOH when immobilized microperoxidase was used as the catalyst. Using immobilized cytochrome $c$ as the catalyst, the ratio of sensitivity was about 80 . This coincides with the figures for free microperoxidase and free cytochrome $c$ as the catalysts. ${ }^{3,17)}$

As microperoxidase is autooxidizable, ferrous microperoxidase is oxidized with oxygen. ${ }^{16,17)}$ On the other hand, cytochrome $c$ is 
not autooxidizable, so ferrocytochrome $c$ is oxidized slowly to ferricytochrome $c .{ }^{18)}$ TresylToyopearl-cytochrome $c$ reduced with ascorbate showed $38 \%$ of the chemiluminescence compared with that catalyzed by the cytochrome without reduction. Reoxidation of the reduced cytochrome $c$ restored the efficiency of chemiluminescence to $77 \%$. When FormylToyopearl was used as the immobilization support, SCBH or DMAB have been used as the reductant. The immobilized cytochrome $c$ might be reduced, and it could not then catalyze the chemiluminescence reaction. This evidence shows that immobilized cytochrome $c$ catalyzed the chemiluminescence reaction by the same mechanism as that for free cytochrome $c$ catalyzing lipid peroxidation. ${ }^{1)}$

Even if the catalysis were immobilized, microperoxidase still showed a higher steady state intensity of chemiluminescence dependent on luminol and hydroperoxide than cytochrome $c$ did. However, the later was superior to the former from the points of view of stability and cost. Moreover, the immobilization of cytochrome $c$ changed the steady-state intensity of chemiluminescence as shown in Fig. 3, so we are now improving its catalytic nature by chemical modification.

Acknowledgment. This work was partly supported by a grant from the Japan Agricultural Research Foundation.

\section{References}

1) R. M. Kaschnitz and Y. Hatefi, Arch. Biochem. Biophys., 171, 292 (1975).

2) H. R. Schroeder, R. C. Boguslaski, R. J. Carrico and R. T. Buckler, in "Methods in Enzymology," Vol. 57, ed. by L. Packer, Academic Press, New York, 1978, pp. 424-445.

3) Y. Yamamoto, M. H. Brodsky, J. C. Baker and B. N. Ames, Anal. Biochem., 160, 7 (1987).

4) T. Miyazawa, K. Fujimoto and T. Kaneda, Agric. Biol. Chem., 51, 2569 (1987).

5) T. Miyazawa, K. Yasuda, K. Fujimoto and T. Kaneda, Anal. Lett., 21, 1033 (1988).

6) K. Hool and T. A. Nieman, Anal. Chem., 59, 869 (1987).

7) Y. Lee, I. Jablonski and M. DeLuca, Anal. Biochem., 80, 496 (1977).

8) T. M. Freeman and W. R. Seitz, Anal. Chem., 50, 1242 (1978).

9) H. A. Harburg and P. A. Loach, J. Biol. Chem., 235, 3640 (1966).

10) E. Margoliash and N. Frohwirt, Biochem. J., 71, 570 (1959).

11) M. Roza and A. Francke, Biochim. Biophys. Acta, 316, 72 (1973).

12) J. Terao and S. Matsushita, J. Biol. Chem., 42, 667 (1978).

13) C. H. Lea, Proc. Roy. Soc. Sci. Ser B, 108, 175 (1931).

14) G. A. Russell, J. Am. Chem. Soc., 79, 3871 (1957).

15) P. B. Merkel and D. R. Kearns, J. Am. Chem. Soc., 94, 7244 (1972).

16) C. L. Tsou, Biochem. J., 49, 362 (1951).

17) C. L. Tsou, Biochem. J., 49, 367 (1951).

18) W. D. Butt and D. Keilin, Proc. Roy. Soc. Sci., Ser. $B, 156,429$ (1962). 